\title{
Estimation of dilution in laser cladding based on energy balance approach using regression analysis
}

\author{
SHITANSHU SHEKHAR CHAKRABORTY ${ }^{1, *}$ and SAMIK DUTTA ${ }^{2}$ \\ ${ }^{1}$ Materials Processing and Microsystems Laboratory, CSIR-Central Mechanical Engineering Research Institute, \\ Durgapur 713209, India \\ ${ }^{2}$ Surface Engineering and Tribology Group, CSIR-Central Mechanical Engineering Research Institute, \\ Durgapur 713209, India \\ e-mail: ss.chakraborty@cmeri.res.in; situspeaks@gmail.com; s_dutta@cmeri.res.in; samikhere@gmail.com
}

MS received 31 December 2018; revised 1 April 2019; accepted 22 April 2019; published online 24 May 2019

\begin{abstract}
Laser cladding is a complex manufacturing process involving more than 19 variables related to laser source, workpiece movement, powder-substrate material combinations, clad geometry, powder flow dynamics, shrouding gas flow and so on. Significant research efforts have been directed to analytical-numericalempirical modelling of laser cladding and also in-process monitoring and control of the process. Still, due to complicated physics there is a dearth of simple analytical model for estimation of dilution in laser cladding. Its experimental measurement requires suitable micrographs of the clad cross section perpendicular to the clad path. This is a time-consuming and destructive way of measurement. Numerical models are time consuming to evaluate and hence not suitable for fast decision making or real-time control implementation. The analytical models available, despite having many approximations, are a little complicated, require fair amount computer programming and often need suitable prior guessing of range of output parameters for adjustment of constant values in the models. This poses some challenges for use and having an intuitive guidance, for a beginner/ unskilled operator. Besides, their complexity may erect barrier in the way of their implementation for real time monitoring and control. This work proposes a simple linear regression model, formed based on energy balance approach, to estimate dilution in laser cladding. After fitting to a set of data, within a suitable process parameterwindow, for a particular clad-substrate material combination, this model can estimate dilution as a function of input/easily measureable parameters, viz. laser power, scan speed, clad width and clad height. The model fitted well to the experimental data taken from literature.
\end{abstract}

Keywords. Laser cladding; estimation of dilution; energy balance; linear regression.

\section{Introduction}

Laser cladding is the process of depositing a material, named "clad material", onto another material, named "substrate material", by melting injected/preplaced powder or fed wire of the former one with the help of thermal energy provided by a laser beam. Cladding is usually done to protect the substrate by covering it with a hard and wear resistant material. Cladding serves the role of providing desired surface properties viz. hardness, wear resistance, etc. eliminating the need of the entire part being made of hard-wear resistant material which is costly in terms of the material and its processing as well. Laser as a heat source for cladding has surpassed electron beam or ion beam mainly because of being more flexible, cost effective and having no requirement of high vacuum or shielding chamber (for e.g., to shield operator from probable x-ray

*For correspondence generated by electron beam) [1]. Besides, laser cladding is endowed with the advantages like minimal heat effects, distortion, dilution; amenability to automation and ability to generate coatings with non-equilibrium microstructures and superior surface properties [2]. Usually the substrate is also melted by a depth amounting to around $10-30 \%$ of the height of the clad layer in laser cladding [3]. The melt layer of the substrate consumes in itself a significant portion of the clad material. In the clad cross section perpendicular to the clad path, if $A_{\mathrm{c}}$ and $A_{\mathrm{s}}$ be the area above and below the initial substrate surface, then a term called dilution (say $\lambda$ ) can be defined as (figure 1),

$$
\lambda=\frac{A_{\mathrm{s}}}{A_{\mathrm{c}}+A_{\mathrm{s}}}=\frac{\frac{\pi}{4} h_{\mathrm{s}} w_{\mathrm{p}}}{\frac{\pi}{4} h_{\mathrm{c}} w_{\mathrm{p}}+\frac{\pi}{4} h_{\mathrm{s}} w_{\mathrm{p}}}=\frac{h_{\mathrm{s}}}{h_{\mathrm{c}}+h_{\mathrm{s}}}
$$

Here. $h_{\mathrm{p}}, h_{\mathrm{s}}$ and $w_{\mathrm{p}}$ are the height of the clad above the initial substrate surface, melt depth below the surface and the width of the clad pass respectively. Both the clad cross 


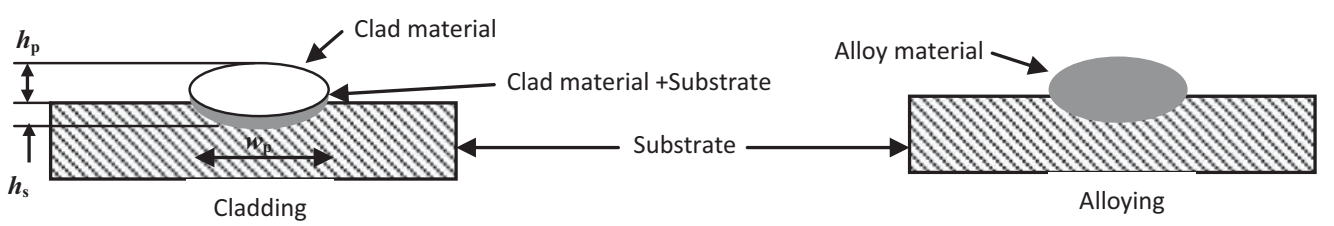

Figure 1. Difference between cladding and alloying.

section above and the melt depth below the initial substrate surface can be ideally assumed as semi-ellipse (figure 1) [4-6] or circular [5-7]. However, elliptical clad layer cross section is preferred because circular clad layer cross section indicates poor wet-ability of the clad layer, porosity and poor surface finish [5]. In laser surface alloying this dilution is much higher as compared to the laser cladding as illustrated in figure 1. Often multiple clad layers are deposited onto the substrate. In such case, if the clad layer geometry is different from the substrate-surface profile, the process is termed as "laser additive manufacturing", which is considered as a different process. In case of laser additive manufacturing, the deposited part is usually detached from the substrate base, and hence, a relatively weaker support structure is built in between the deposited part and the substrate surface. However, it is not always necessary to detach the additively manufactured layer from the surface. As per the ASTM standard F2792, additive manufacturing is a "process of joining materials to make objects from 3D model data, usually layer upon layer, as opposed to subtractive manufacturing methodologies."

At least 19 parameters are involved in laser cladding as listed in [8]. These are related to laser source, motion of workpiece, powder-substrate material combinations, clad geometry, powder flow dynamics, shrouding gas flow and so on. Significant research efforts are being invested for analytical [4-7], numerical [2, 9-11] and empirical modelling [12], and in-process monitoring and control [13-20] of laser cladding process. The numerical models are both two dimensional (2D) $[2,11]$ and three dimensional (3D) [9, 10]. Hoadley et al [11] in their 2D numerical model assumed the heat flow to be confined in the plane formed by the axis of cladding motion and the axis along the depth of the surface. This plane is often called as "longitudinal plane" to distinguish it from the "transverse plane" which is perpendicular to the clad velocity vector. However, near the end of the momentous melt pool, heat flow is essentially in the transverse cross section. This is because the temperature gradient in the transverse cross-section is much larger than that in the longitudinal section. Therefore, neglecting heat flow outside the transverse plane, Kim and Peng [2] developed a 2D model assuming the heat flow to be confined in the transverse cross-section. However, as the process is essentially three dimensional (3D), 3D numerical models are more realistic. Numerical models though can take into account the temperature dependent material properties and other realistic assumptions, analytical models are fast to compute. The analytical models assumed a quasi-steady state of laser cladding process [4-7]. Multiple responses such as clad track width, clad height, cladding zone temperature, cooling rate, etc. have been successfully monitored in real time [9, 13-20]. However, practical implementation of real time control have been so far reported for either laser power or scan speed or powder flow rate. To the best of the authors' knowledge, simultaneous control of multiple output variables based on multiple input (MIMO control) has not been implemented on laser cladding set-up physically.

Due to complicated physics of the process, there is a scarcity of simple analytical model for estimation of dilution in laser cladding. Its experimental measurement requires suitable micrographs of the clad cross section perpendicular to the clad path [3]. This is a time-consuming and destructive way of measurement. The analytical models available contains a lot of assumptions like constant material properties, etc. [4-7] and yet takes the complementary help of empirical relations and guess of possible range of output variables [5]. Besides, expressions of analytical formulations are not so simple. Their implementation requires a fair amount of computer programming. This poses some challenges for use and having an intuitive guidance, specially for a beginner/unskilled operator. Apart from these, their complexity may erect barrier in the way of their implementation for real time monitoring-control. This work proposes a simple linear regression model, formed based on energy balance approach, to estimate dilution in laser cladding. After fitting to a set of data, within a suitable process parameter-window, for a particular clad-substrate material combination, this model can estimate dilution as a function of input/easily measureable parameters, viz. laser power, scan speed, clad width and clad height. The model fitted well to the experimental data taken from [4] and [2]. Dilution has been monitored in real time indirectly using the width of the clad track [16]. The current model proposes use of both the width and height of the clad track. Both of these quantities can be monitored in real time. Usually regression models involve a lot of terms, including quadratic terms and product terms of the parameters. Not only a large number of experimental data shall be required to develop such a model, implementing 
such a model for real time control shall also be difficult. Therefore, the current model, which involves only three coefficients to be found out from regression analysis, can be helpful. However, this work made no attempt in real time monitoring or control of dilution. This may be attempted in future research. Qu et al [21] have shown significant effect of pre-placed layer thickness on dilution in laser cladding. This model does not consider this. Hence, it is applicable to laser cladding by blown powder method only, not to laser cladding by pre-placed powder method.

\section{Formulation of analytical model}

The analytical model of laser cladding developed here is based on the principle of conservation of energy and the following assumptions:

i. Only the laser beam is adding energy to the process. No other energy is added/absorbed by chemical reaction or solution/precipitation of particles. The kinetic energy of the blown clad powder is also neglected. Convection and radiation are neglected because of having less significant effect [2], [4], [7].

ii. A quasi-steady state prevails during the clad track deposition. This assumption again implies neglecting edge-effects and any irregularity in the powder flow. Also, latent heat of fusion is assumed to be balanced by latent heat of solidification, as done by Kim and Peng [2], Pinkerton and Li [7] and others.

iii. A constant fraction of the input laser energy is lost because of the following reasons:

a) being carried away by the loose powder particle (which does not form the clad layer) and the career gas;

b) being scattered by the powder stream and reflected back from the clad-substrate region.

The rest is input to the cladding process. A part of this assumption, in other words, implies constant absorptivity of the laser energy into the clad zone.

iv. Properties of both the clad and the substrate materials, vary over the temperature range encountered during the cladding process. However, these can be assumed to be constant at some mean value, without introducing much error into the calculation. This is the same assumption as made in other analytical models $[4,6,7]$.

$v$. The entire clad layer has been assumed to reach an average peak temperature $T_{\text {avg }}^{\mathrm{c}}$ which is in between the melting and vaporizing temperature of the clad material (some portion of the powder may vaporize). The substrate has been assumed to be just melted without any superheating.

We can write then,

\begin{tabular}{lc}
\hline $\begin{array}{l}\text { Energy input per clad track } \\
\text { (excluding the energy } \\
\text { reflected and scattered, } \\
\text { energy carried away by } \\
\text { the loose powder and } \\
\text { carrier gas, and, the } \\
\text { kinetic energy of the } \\
\text { clad powder influx), }\end{array}$ & $\begin{array}{c}\text { Energy required to melt } \\
\text { and superheat the } \\
\text { volume of the clad } \\
\text { track, } E_{\text {track }}+\text { Energy } \\
\text { required to vaporize a } \\
\text { portion of the clad }\end{array}$ \\
material, $E_{\text {vapour }}+$ \\
Energy required to melt \\
the diluted substrate \\
volume, $E_{\text {substrate }}+$ \\
Energy loss due to heat \\
conduction into the \\
substrate, $E_{\text {conduction }}+$ \\
Energy loss due to \\
convection and \\
radiation to the ambient, \\
$E_{\text {conv }}$
\end{tabular}

Out of these, $E_{\text {vapour }}$ gives a measure of the loss of clad material due to vaporization and hence, should be minimized. $E_{\text {conv }}$ can be neglected for practical purposes [3-7]. We can club them together into an error term, $e$ per unit clad track length, $l_{\mathrm{c}}$. Thus we can write,

$$
E_{\text {input }}=E_{\text {track }}+E_{\text {substrate }}+E_{\text {conduction }}+e . l_{\mathrm{c}}
$$

Assuming the clad track as well as the melt volume of the substrate to be half elliptical cylinders as shown in figure 1 we can estimate their volumes as, $\frac{\pi}{4} h_{\mathrm{c}} w_{\mathrm{p}} l_{\mathrm{c}}$ and $\frac{\pi}{4} h_{\mathrm{s}} w_{\mathrm{p}} l_{\mathrm{c}}$, respectively.

$$
E_{\text {input }}=\eta_{1} \frac{P}{v} l_{\mathrm{c}}
$$

Here, $\eta_{1}$ is the fraction of the laser energy being coupled into the cladding process. This excludes the energy reflected back from the workpiece, scattered by the clad powder and that carried away by the loose powder and carrier gas. $P$ and $v$ are the laser power and scan speed, respectively.

Hence, assuming that latent heat of fusion is balanced by latent heat of solidification, $E_{\text {track }}$ and $E_{\text {substrate }}$ can be estimated as follows.

$$
\begin{aligned}
E_{\text {track }}= & \frac{\pi}{4} h_{\mathrm{c}} w_{\mathrm{p}} l_{\mathrm{c}} \rho^{\mathrm{c}} C_{\mathrm{p}}^{\mathrm{c}}\left(T_{\mathrm{m}}^{\mathrm{c}}-T_{0}^{\mathrm{c}}\right) \\
& +\frac{\pi}{4} h_{\mathrm{c}} w_{\mathrm{p}} l_{\mathrm{c}} \rho^{\mathrm{c}^{\prime}} C_{\mathrm{p}}^{\mathrm{c}^{\prime}}\left(T_{\mathrm{avg}}^{\mathrm{c}}-T_{\mathrm{m}}^{\mathrm{c}}\right) \\
E_{\text {substrate }}= & \frac{\pi}{4} h_{\mathrm{s}} w_{\mathrm{p}} l_{\mathrm{c}} \rho^{\mathrm{s}} C_{\mathrm{p}}^{\mathrm{s}}\left(T_{\mathrm{m}}^{\mathrm{s}}-T_{0}^{\mathrm{s}}\right) \\
= & \frac{\lambda}{1-\lambda} \frac{\pi}{4} h_{\mathrm{c}} w_{\mathrm{p}} l_{\mathrm{c}} \rho^{\mathrm{s}} C_{\mathrm{p}}^{\mathrm{s}}\left(T_{\mathrm{m}}^{\mathrm{s}}-T_{0}^{\mathrm{s}}\right)
\end{aligned}
$$

Here, $\rho^{\mathrm{c}}, C_{\mathrm{p}}^{\mathrm{c}}, T_{\mathrm{m}}^{\mathrm{c}}$, and $T_{0}^{\mathrm{c}}$ denote density, specific heat, melting temperature and initial temperature of the clad material, respectively, in solid state. While, $\rho^{\mathrm{s}}, C_{\mathrm{p}}^{\mathrm{s}}, T_{\mathrm{m}}^{\mathrm{s}}$, and $T_{0}^{\mathrm{s}}$ denote the corresponding quantities for the substrate material. $\rho^{\mathrm{c}^{\prime}}$ and $C_{\mathrm{p}}^{\mathrm{c}^{\prime}}$ denote the mean value of density and specific heat of the clad material at the liquid state. There is 
a reason for assuming the initial temperatures of the clad and the substrate materials not to be equal to the ambient temperature, say $T_{0}$. In case of laser cladding with blown clad powder, the powder is often heated to certain temperature $T_{0}^{\mathrm{c}}$, to reduce moisture content and also to ensure free flow through pipe and powder injection nozzle. The substrate is also sometimes pre-heated to a certain temperature $T_{0}^{\mathrm{s}}$, to minimize thermal distortion due heat from the cladding process. For simplicity, we further assume $E_{\text {conduction }}$ to be a constant fraction, $\eta_{2}\left(<\eta_{1}\right)$ of the input line energy $\left(\frac{P}{v}\right)$, i.e.,

$$
E_{\text {conduction }}=\eta_{2} \frac{P}{v} l_{\mathrm{c}}
$$

Combining Eqs. (2)-(6) we get,

$$
\begin{aligned}
& \eta_{1} \frac{P}{v} l_{\mathrm{c}}=\frac{\pi}{4} h_{\mathrm{c}} w_{\mathrm{p}} l_{\mathrm{c}}\left(\rho^{\mathrm{c}} C_{\mathrm{p}}^{\mathrm{c}}\left(T_{\mathrm{m}}^{\mathrm{c}}-T_{0}^{\mathrm{c}}\right)+\rho^{\mathrm{c}^{\prime}} C_{\mathrm{p}}^{\mathrm{c}^{\prime}}\left(T_{\mathrm{avg}}^{\mathrm{c}}-T_{\mathrm{m}}^{\mathrm{c}}\right)\right) \\
& +\frac{\lambda}{1-\lambda} \frac{\pi}{4} h_{\mathrm{c}} w_{\mathrm{p}} l_{\mathrm{c}} \rho^{\mathrm{s}} C_{\mathrm{p}}^{\mathrm{s}}\left(T_{\mathrm{m}}^{\mathrm{s}}-T_{0}^{\mathrm{s}}\right)+\eta_{2} \frac{P}{v} l_{\mathrm{c}}+e l_{\mathrm{c}}
\end{aligned}
$$

Which becomes,

$$
\begin{gathered}
\eta \frac{P}{v}=\frac{\pi}{4} h_{\mathrm{c}} w_{\mathrm{p}}\left(\rho^{\mathrm{c}} C_{\mathrm{p}}^{\mathrm{c}}\left(T_{\mathrm{m}}^{\mathrm{c}}-T_{0}^{\mathrm{c}}\right)+\rho^{\mathrm{c}^{\prime}} C_{\mathrm{p}}^{\mathrm{c}^{\prime}}\left(T_{\mathrm{avg}}^{\mathrm{c}}-T_{\mathrm{m}}^{\mathrm{c}}\right)\right) \\
+\frac{\lambda}{1-\lambda} \frac{\pi}{4} h_{\mathrm{c}} w_{\mathrm{p}} \rho^{\mathrm{s}} C_{\mathrm{p}}^{\mathrm{s}}\left(T_{\mathrm{m}}^{\mathrm{s}}-T_{0}^{\mathrm{s}}\right)+e \\
\text { where }, \eta=\eta_{1}-\eta_{2}
\end{gathered}
$$

In practice, for further generalization, it is safer to assume the width of the molten substrate to be some constant, say $\xi$, multiplied by $w_{\mathrm{p}}$, as the clad cross section may not be very smoothly matching with the cross section of the molten substrate.

Thus Eq. (8) becomes as follows

$$
\begin{aligned}
\frac{P}{v}= & \frac{1}{\eta} \frac{\pi}{4} h_{\mathrm{c}} w_{\mathrm{p}}\left(\rho^{\mathrm{c}} C_{\mathrm{p}}^{\mathrm{c}}\left(T_{\mathrm{m}}^{\mathrm{c}}-T_{0}^{\mathrm{c}}\right)+\rho^{\mathrm{c}^{\prime}} C_{\mathrm{p}}^{\mathrm{c}^{\prime}}\left(T_{\mathrm{avg}}^{\mathrm{c}}-T_{\mathrm{m}}^{\mathrm{c}}\right)\right) \\
& +\frac{1}{\eta} \frac{\lambda}{1-\lambda} \frac{\pi}{4} h_{\mathrm{c}} \xi w_{\mathrm{p}} \rho^{\mathrm{s}} C_{\mathrm{p}}^{\mathrm{s}}\left(T_{\mathrm{m}}^{\mathrm{s}}-T_{0}^{\mathrm{s}}\right)+\frac{1}{\eta} e
\end{aligned}
$$

Hence, for a particular clad-substrate material combination, one can assume the following regression model for estimating dilution, $\lambda$ as a function of input parameters: $P$ and $v$, and easily measurable parameters: $h_{\mathrm{c}}$ and $w_{\mathrm{p}}$ as shown in Eq. (10).

$$
\frac{P}{v}=C_{1} h_{\mathrm{c}} w_{\mathrm{p}}+C_{2} \frac{\lambda}{1-\lambda} h_{\mathrm{c}} w_{\mathrm{p}}+C_{3}
$$

where, $C_{1}, C_{2}$, and $C_{3}$ are constants, to be obtained from data fitting. If, line energy, clad height and clad width are expressed in $\mathrm{J} / \mathrm{mm}, \mathrm{mm}$ and $\mathrm{mm}$ respectively, units of $C_{1}$, $C_{2}$ and $C_{3}$ shall be $\mathrm{J} / \mathrm{mm}^{3}, \mathrm{~J} / \mathrm{mm}^{3}$ and $\mathrm{J} / \mathrm{mm}$, respectively.

\section{Validation of the developed model}

Fathi et al [4] developed an analytical model of laser cladding. They validated that with the help of results from the experiments, they carried out on pulsed laser cladding. Their experimental data could be fitted well with $R^{2}$ value (coefficient of determination, which denotes degree of fitting of the regression model) of 0.9877 . They used Stainless steel grade 303-L powder (Fe 70\%:Cr 17\%:Ni 13\% wt\%) with particle size of $50 \mu \mathrm{m}$ as the clad material and sandblasted mild steel plates $(0.25-0.28 \% \mathrm{C} ; 0.6-1.2 \% \mathrm{Mn})$ with dimensions of $200 \times 30 \times 5 \mathrm{~mm}^{3}$ as the substrate material. Table 1 lists the variables of Eq. (10). From the graphs reported, using " plot digitizer' software, $h_{\mathrm{c}}, w_{\mathrm{p}}$ and $\lambda$ were obtained. Fitted values of $C_{1}-C_{3}$ are also indicated along with $R^{2}$.

Figure 2 shows a nearly linear correlation between the fitted and predicted dilution.

\begin{tabular}{|c|c|c|c|c|c|}
\hline Laser power, $P(\mathrm{~W})$ & $\begin{array}{l}\text { Scan speed, } \\
v(\mathrm{~mm} / \mathrm{s})\end{array}$ & $\begin{array}{l}\text { Clad width, } w_{\mathrm{p}} \\
\quad(\mathrm{mm})\end{array}$ & $\begin{array}{l}\text { Clad height, } h_{\mathrm{c}} \\
\quad(\mathrm{mm})\end{array}$ & $\begin{array}{l}\text { Dilution } \\
\text { fraction, } \lambda\end{array}$ & $\begin{array}{c}\text { Fitted } \\
\text { constants }\end{array}$ \\
\hline \multirow{10}{*}{$\begin{array}{l}=\text { Pulse energy }(\mathrm{J}) \times \text { Pulse repetition rate }(\mathrm{Hz}) \\
=5 \times 90=450\end{array}$} & 1 & 1.22 & 1.29 & 0.00 & $C_{1}=291.56$ \\
\hline & 1.5 & 1.16 & 0.85 & 0.00 & $C_{2}=84.96$ \\
\hline & 2 & 1.36 & 0.44 & 0.22 & $C_{3}=8.02$ \\
\hline & 2.5 & 1.35 & 0.33 & 0.35 & \\
\hline & 3 & 1.39 & 0.32 & 0.35 & \\
\hline & 3.75 & 1.48 & 0.22 & 0.49 & $R^{2}=0.9877$ \\
\hline & 5 & 1.41 & 0.14 & 0.60 & \\
\hline & 6.25 & 1.24 & 0.13 & 0.59 & \\
\hline & 7.5 & 1.33 & 0.10 & 0.64 & \\
\hline & 10 & 1.28 & 0.08 & 0.68 & \\
\hline
\end{tabular}

The laser beam energy is incident on the substrate through the cloud of ejected clad powder. With increasing scan speed, powder ejected per unit scan length reduces if the powder flow rate is constant. Hence, shielding of laser beam by the powder cloud also reduces. This may enable melting the substrate to higher depth causing higher clad layer dilution. Increasing scan speed beyond a certain limit

Table 1. Variables of the regression model obtained from [4] and fitted constants. 


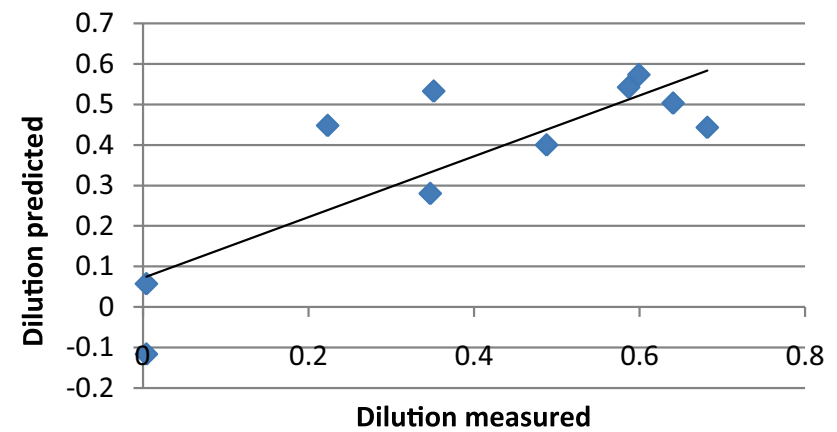

Figure 2. Correlation between the dilution measured [4] and the dilution predicted using the current model.

Table 2. Variables of the regression model obtained from [2] and fitted constants.

\begin{tabular}{lccccc}
\hline $\begin{array}{l}\text { Laser scan } \\
\text { speed, } \\
v(\mathrm{~mm} / \mathrm{s})\end{array}$ & $\begin{array}{c}\text { Laser } \\
\text { power, } \\
P(\mathrm{~W})\end{array}$ & $\begin{array}{c}\text { Clad } \\
\text { width, } \\
(\mathrm{mm})\end{array}$ & $\begin{array}{c}\text { Clad } \\
\text { height, } \\
(\mathrm{mm})\end{array}$ & Dilution & $\begin{array}{c}\text { Fitted } \\
\text { constants }\end{array}$ \\
\hline 3.33 & 380 & 3.23 & 0.77 & 0.59 & $C_{1}=9.46$ \\
& 390 & 3.41 & 0.86 & 0.62 & $C_{2}=-1.31$ \\
& 400 & 3.59 & 0.95 & 0.64 & $C_{3}=95.58$ \\
& 410 & 3.79 & 1.06 & 0.66 & \\
& 420 & 3.99 & 1.15 & 0.68 & \\
& 430 & 4.17 & 1.24 & 0.70 & $R^{2}=0.9985$ \\
& 440 & 4.37 & 1.35 & 0.71 & \\
& 450 & 4.58 & 1.46 & 0.73 & \\
\hline
\end{tabular}

may again reduce substrate melting and dilution due to less availability of line energy. However, this limit might be outside the scan speed range explored in the literature [4], from where experimental data for validation of the current model were taken. Verification of the developed model expressed by Eq. (10) requires clad width, height and dilution fraction for the same laser power and scan speed combination. Literature on laser cladding by blown powder method, presenting simultaneously these three data for the same combination of power and scan speed, is scarce. However, quite interestingly, the model fitted to the experimental data on wire fed laser cladding, as given by Kim and Peng [2] with an $R^{2}$ value of 0.9985 . They clad inconel 600 wire having $0.2 \mathrm{~mm}$ diameter on the same substrate material with the help of Nd:YAG laser. The experimental data is provided in table 2 .

\section{Conclusion}

A simple-to-use linear regression model, formed based on energy balance approach, to estimate dilution in laser cladding by blown powder method is presented here. This model can estimate dilution as a function of input/easily measureable parameters, viz. laser power, scan speed, clad width and clad height. It only requires prior fitting of three regression constants to a set of data, within a process parameter-window, suitable for a particular clad-substrate material combination. The model fitted well to the experimental data taken from literature on laser cladding by both blown powder method and wire fed method.

\section{List of symbols

$\lambda$

$A_{\mathrm{s}}$ substrate surface

dilution (fraction)

clad cross sectional area above initial cross sectional area of clad layer dilution below initial substrate surface

$h_{\mathrm{c}}$

$h_{\mathrm{s}}$ clad height above initial substrate surface clad layer dilution depth below initial substrate surface

\section{$w_{\mathrm{p}}$}

$l_{\mathrm{c}}$

$\eta_{1}$

width of the clad pass (perpendicular to the clad velocity vector)

length of the clad pass (along the clad velocity vector)

fraction of the laser energy being coupled into the cladding process

laser power

$P$

$v$

$\rho^{\mathrm{c}}$

laser scan speed

density of the clad material in solid state specific heat of the clad material in solid state

$\rho^{\mathrm{c}^{\prime}}$

density of the clad material in liquid state specific heat of the clad material in liquid state

$T_{\mathrm{m}}^{\mathrm{c}}$

$T_{0}^{\mathrm{c}}$

$\rho^{\mathrm{s}}$ melting temperature of the clad material initial temperature of the clad material density of the substrate material in solid state

$C_{\mathrm{p}}^{\mathrm{s}} \quad$ specific heat of the substrate material in solid state

$T_{\mathrm{m}}^{\mathrm{s}} \quad$ melting temperature of the substrate

$T_{0}^{\mathrm{s}} \quad$ material $\quad$ initial temperature of the substrate material

$\eta_{2} \quad$ fraction of input energy being conducted into the substrate

$C_{1}, C_{2}$, and constants of regression

$C_{3}$

\section{References}

[1] Majumdar J D and Manna I 2003 Laser processing of materials. Sadhana 28: 495-562

[2] Kim J D and Peng Y 2000 Melt pool shape and dilution of laser cladding with wire feeding. J. Mater. Process. Tech. 104: 284-293

[3] Toyserkani E, Khajepour A and Corbin S F 2004 Laser cladding. CRC press, Durgapur, India, pp. 21 
[4] Fathi A, Toyserkani E, Khajepour A and Durali M 2006 Prediction of melt pool depth and dilution in laser powder deposition. J. Phys. D Appl. Phys. 39: 2613-2623

[5] Pinkerton A J and Li L 2004 Modelling the geometry of a moving laser melt pool and deposition track via energy and mass balances. J. Phys. D Appl. Phys. 37: 1885-1895

[6] Bamberger M, Kaplan W D, Medres B and Shepeleva L 1998 Calculation of process parameters for laser alloying and cladding. J. Laser. Appl. 10: 29-33

[7] Colaco R, Costa L, Guerra R and Vilar R 1996 A simple correlation between the geometry of laser cladding tracks and the process parameters. In: Laser processing: surface treatment and film deposition. Springer, Dordrecht, pp. 421-429

[8] Kahlen F J and Kar A 2001 Tensile strengths for laser-fabricated parts and similarity parameters for rapid manufacturing. J. Manuf. Sci. E.-T. ASME 12: 38-44

[9] Hu D and Kovacevic R 2003 Sensing, modeling and control for laser-based additive manufacturing. Int. J. Mach. Tool Manuf. 43: 51-60

[10] Toyserkani E, Khajepour A and Corbin S 2003 Three-dimensional finite element modeling of laser cladding by powder injection: effects of powder feedrate and travel speed on the process. J. Laser Appl. 15: 153-160

[11] Hoadley A and Rappaz M 1992 A thermal model of laser cladding by powder injection. Metall. Trans. B 23: 631-642

[12] Boddu M R, Musti S, Landers R G, Agarwal S and Liou F W 2001 Empirical modeling and vision based control for laser aided metal deposition process. In: Proceedings of the Solid Freeform Fabrication Symposium, pp. 452-459

[13] Farshidianfar M H, Khajepour A and Gerlich A 2016 Realtime control of microstructure in laser additive manufacturing. Int. J. Adv. Manuf. Technol. 82: 1173-1186
[14] Cao X and Ayalew B 2015 Multivariable predictive control of laser-aided powder deposition processes. In: American Control Conference (ACC), IEEE, pp. 3625-3630

[15] Song L, Bagavath-Singh V, Dutta B and Mazumder J 2012 Control of melt pool temperature and deposition height during direct metal deposition process. Int. J. Adv. Manuf. Technol. 58: 247-256

[16] Rodriguez-Araujo J, Rodriguez-Andina J J, Farina J, Vidal F, Mato J L and Montealegre M A 2012 Industrial laser cladding systems: FPGA-based adaptive control. IEEE Ind. Electron. Mag. 6(4): pp. 35-46

[17] Muvvala G, Karmakar D P and Nath A K 2017 Online monitoring of thermo-cycles and its correlation with microstructure in laser cladding of nickel based super alloy. Opt. Laser Eng. 88: 139-152

[18] Muvvala G, Karmakar D P and Nath A K 2017 Online assessment of $\mathrm{TiC}$ decomposition in laser cladding of metal matrix composite coating. Mater. Des. 121: 310320

[19] Muvvala G, Karmakar D P and Nath A K 2017 Monitoring and assessment of tungsten carbide wettability in laser cladded metal matrix composite coating using an IR pyrometer. J. Alloy. Compd. 714: 514-521

[20] Muvvala G, Karmakar, D P and Nath A K 2018 In-process detection of microstructural changes in laser cladding of insitu Inconel 718/TiC metal matrix composite coating. J. Alloy. Compd. 740: 545-558

[21] Qu C C, Li J, Bai L L, Shao J Z, Song R and Chen J L 2015 Effects of the thickness of the pre-placed layer on microstructural evolution and mechanical properties of the laser-clad coatings. J. Alloy. Compd. 644: 450463 